\title{
Happy Birthday, X-Ray!
}

\section{Jahre Entdeckung der Röntgenstrahlen - Deutsche Röntgen- gesellschaft feiert den International Day of Radiology (IDOR)}

Im angelsächsischen Raum wird dieser Tag bereits seit einigen Jahren begangen, in unseren Breiten genießt er noch keine hohe Bekanntheit: der X-RayDay, der Tag, der an die Entdeckung der Röntgenstrahlung durch Wilhelm Conrad Röntgen am 08. November 1895 erinnert.
Der Vorstand der DRG ist daher dem Aufruf der European Society of Radiology gefolgt, den International Day of Radiology (IDOR) im Bewusstsein der Bevölkerung zu etablieren. Mit verschiedenen PresseAktionen, Radiobeiträgen und elektronischen Informationsmappen informierte die Pressestelle der DRG Journalisten über ein Datum, das die Medizin revolutionierte. Auch die DRG-Mitglieder erhalten Informationsmaterialien zur Auslage in den Wartebereichen von Klinik und Praxis.

Weitere Informationen zum IDOR auf der Aktionsseite der Deutschen Röntgengesellschaft unter

http://www.drg.de/presse/presseinformationen/683

sowie dem Kampagnenportal der ESR unter:

http://www.internationaldayofradiology. com/
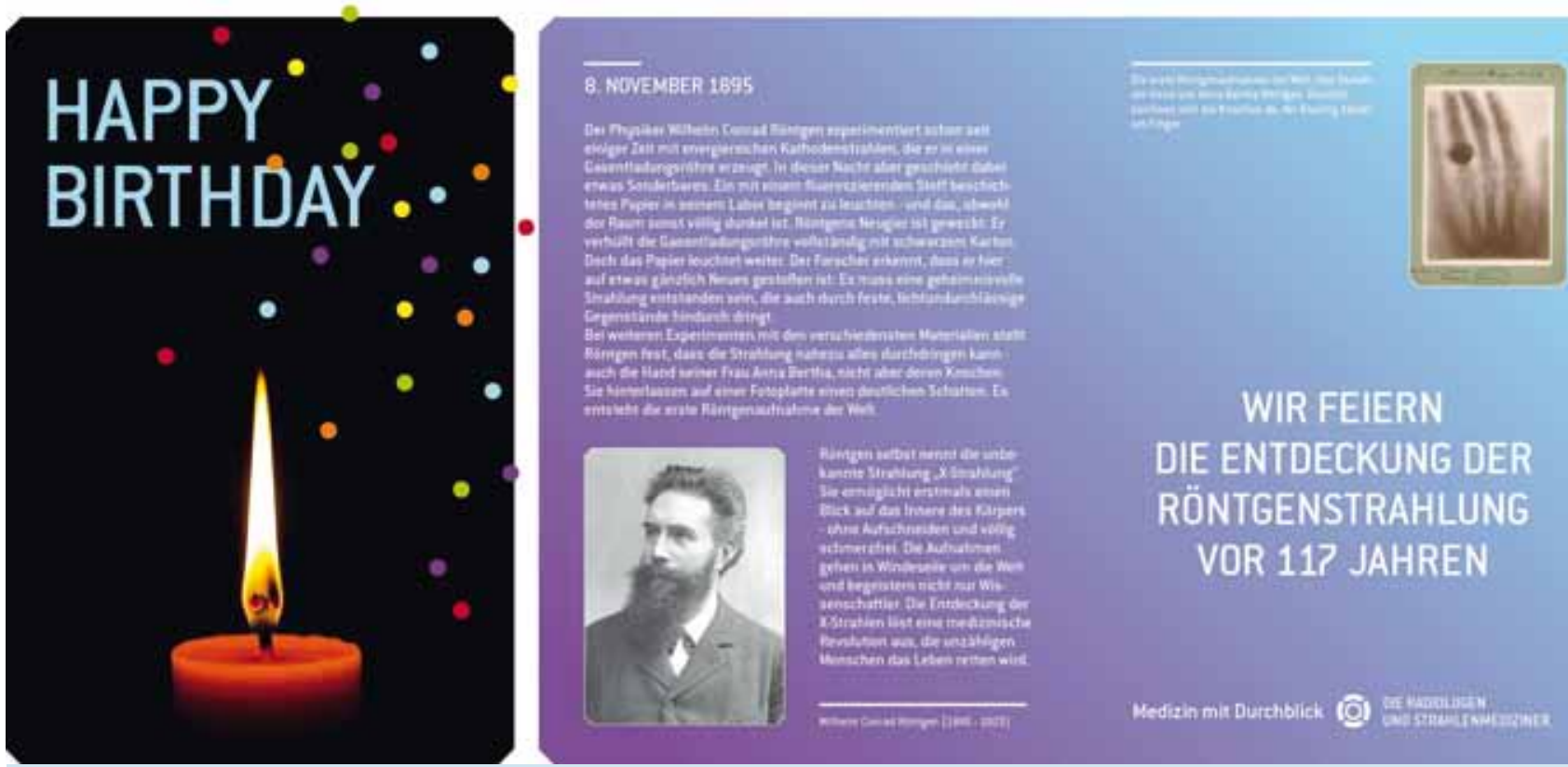

Happy Birthday, X-Ray! - Geburtstagskarte mit Informationen zu den Ereignissen des 08. November 1895. 